\title{
Proposed Occupational Vulnerability Index COVID-19
}

\author{
Ma Teófila Vicente-Herrero', ${ }^{*}$ (), Ma Victoria Ramírez Iñiguez de la Torre ${ }^{1,3,4}$ (i),

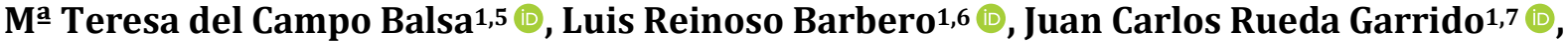 \\ Cristina Santamaría Navarro 8 (i)
}

\author{
${ }^{1}$ Asociación Española de Especialistas en Medicina del Trabajo, Madrid, Spain \\ ${ }^{2}$ Occupational Health and Safety Services of SPP Correos, Valencia, Spain \\ ${ }^{3}$ Occupational Health and Safety Services of SPP Correos, Albacete, Spain \\ ${ }^{4}$ Occupational Health and Safety Services of SPA ITEM-Prevención, Albacete, Spain \\ ${ }^{5}$ Department of Occupational and Prevention at University Hospital Fundación Jiménez Díaz, Universidad Autónoma de Madrid, \\ Madrid, Spain \\ ${ }^{6}$ Occupational Medicine Service Grupo Banco Santander, Madrid, Spain Faculty of Health Sciences, Universidad Internacional de \\ la Rioja, La Rioja, Spain \\ ${ }^{7}$ Occupational Medicine SABIC Medical Services, Cartagena, Spain \\ ${ }^{8}$ University-PDI. Instituto de Matemática Multidisciplinar. Universitat Politècnica de València, Valencia, Spain \\ Email: *vicenteherreromt@gmail.com
}

How to cite this paper: Vicente-Herrero, M.T., Ramírez Iñiguez de la Torre, M.V., del Campo Balsa, M.T., Reinoso Barbero, L., Rueda Garrido, J.C. and Santamaría Navarro, C. (2020) Proposed Occupational Vulnerability Index COVID-19. Occupational Diseases and Environmental Medicine, 8, 175-187.

https://doi.org/10.4236/odem.2020.84014

Received: September 21, 2020

Accepted: October 25, 2020

Published: October 28, 2020

Copyright $\odot 2020$ by author(s) and Scientific Research Publishing Inc. This work is licensed under the Creative Commons Attribution International License (CC BY 4.0).

http://creativecommons.org/licenses/by/4.0/

(c) (i) Open Access

\begin{abstract}
Introduction: Vulnerable is someone who can be hurt or receive injury, physically or morally. The work environment appears as one of the dimensions in which social vulnerability develops and social and occupational vulnerability is defined. The literature does not include an assessment of quantified occupational vulnerability as it already exists in the case of social vulnerability. The aim of this paper is to identify and quantify the variables included in the Protocol for the Assessment of Vulnerability to COVID-19 in such a way that the result can be quantified and allows for a predictive effect on the degree of vulnerability. Methodology: The starting point is the design of a protocol proposal that includes 29 variables. Data is collected from a sample of 420 workers, quantifying the results according to each variable, the overall scores for each group of aspects assessed and, finally, the total score that estimates the degree of vulnerability according to established ranges. Results: Variables that have the highest coefficient and, therefore, the greatest weight in the probability of reaching a group of high or medium vulnerability are cardiovascular disease, cancer, and coagulation alteration. The weight of the labour aspects due to inadequate working conditions stands out. Conclusions: The results obtained with this protocol allow us to make a quantified assessment of labour vulnerability to COVID-19 by integrating individual va-
\end{abstract}


riables of the worker, his working conditions and the preventive actions of his company against COVID-19, and can be useful as an Occupational Vulnerability Index (OVI).

\section{Keywords}

COVID-19 Index, Occupational Vulnerability, Occupational Health, Occupational Medicine

\section{Introduction}

According to the Royal Spanish Academy dictionary, vulnerable is someone who can be hurt or receive injury, physically or morally [1]. However, depending on the discipline that takes it into consideration, the concept of vulnerability has different meanings.

Social vulnerability is the product of social processes that generate unequal exposure to risk in situations of crisis and stress, implying that certain individuals and groups, such as older adults or ethnic minorities, are more prone to risks and inequalities with repercussions on their health [2].

The work world, appears as one of the dimensions in which social vulnerability develops and social and labour vulnerability is defined, alluding to incapacity, defencelessness, and job insecurity and, consequently, to health services, education and the right to social security [3].

Vulnerability, in health science, is the likelihood of being affected by a substance or risk more than is normal for your age and sex, either as a result of increased susceptibility to the effects of that substance or risk, or as a result of a higher than average level of exposure [4]. In this case, the probability of more serious consequences in case of COVID-19 infection is higher.

The publications done during the COVID-19 pandemic are oriented, especially in the United States, towards studies in the field of social vulnerability and include an applicable term for its assessment and quantification, the Social Vulnerability Index (SVI), based on the percentile of social vulnerability in a geographical area towards disasters, and its sub-components (socio-economic status, household composition, minority status and type of housing/accessibility of transport or poor air quality) and relate it to the fatality rate (CFR) and the incidence of COVID-19 [5] [6]. This makes easier the implementation of public policy interventions to help alleviate the pandemic burden on the most socially vulnerable population by reducing inequalities and thus health impacts [7].

Also, in 45 countries in Europe, social factors, such as advanced age or pre-existing chronic health conditions, have been considered, taking into account that may imply a greater risk of developing serious health consequences due to COVID-19. The years lost due to disability (YLD) are taken as a reference marker to estimate the prevention of non-fatal consequences of the disease in relation to geographical vulnerability to COVID-19 [8]. 
In Spain, the health authorities' guidelines for making decisions on the workers' vulnerability due to COVID-19 infection effects, have been based on the assessment of personal aspects: age [9]; pregnancy [10] [11] and the morbidities that have had an impact throughout the different phases of the pandemic [12]: diabetes, arterial hypertension [13] [14], obesity [15] [16], cancer, cardiovascular disease [17] [18], chronic lung disease [19], chronic liver disease [20] [21] and immunosuppression [22]; the risk of exposure to COVID-19 in the workplace (particularly in the health [23], social care sector [24], and in contact with the public).

The literature does not include an assessment of quantified labour vulnerability as it already exists in the case of social vulnerability, so that all the aspects involved in a worker's situation are integrated with regard to the increased risk of infection by the COVID-19 virus and its consequences.

\section{Objective}

The objective of this work is to identify and quantify the variables included in the Protocol for Vulnerability Assessment against COVID-19 [25] that can influence whether a person reaches a medium/high degree of risk of vulnerability and that can have a predictive effect on the degree of vulnerability. It is proposed to use the results obtained with the application of the protocol as an index of occupational vulnerability.

\section{Material and Method}

The starting point is the design of a previously published proposal protocol that includes 29 variables. A computerized database of the protocol contains data from a sample of 420 workers, all of whom were previously assessed by the Prevention Service of their company in accordance with the Health Spanish Ministry evaluation criteria of the published in the respective official bulletins throughout the different pandemic stages [26].

Workers classified as vulnerable to COVID 19 infection and included in this protocol were placed in home isolation during the COVID-19 alert period in Spain, with the temporary disability coverage provided by the National Social Security Institute (INSS) and with extraordinary occupational accident classification for economic compensation purposes [27]. They belong to different labor sectors, with prevention services coverage, both their own and those of others, within the Spanish regulations on prevention of labor risks [28]. The protocol does not include personal identification data for the purposes of the Spanish Data Protection Ac [29], since the sole purpose is to make an initial assessment of the results obtained for epidemiological and preventive purposes.

The results are quantified following the established protocol and scores are obtained for each of the versions and overall scores for each group of aspects evaluated. Finally, the total score is obtained according to the score obtained in each of the groups. The degree of vulnerability arises from the score assigned to the different aspects assessed and shows a value ranging from a minimum of 0 
points to a maximum of 12 points (considered 0 - 3 points low grade-Not Vulnerable; 4 - 7 points medium grade-Presents Vulnerability to COVID-19 with medium risk complications; 8 - 12 points high grade-Presents Vulnerability to COVID-19 with high risk complications) [30].

The statistical treatment of the data is carried out by means of comparison: The mean value of the vulnerability score is compared according to the groups defined by the variables collected in the survey, using the Mann-Whitney $U$ test (non-parametric version of the test Student-Fisher $t$ ) to contrast the difference of the means. In all calculations, a value of $p$ less than 0.05 is accepted as a level of significance.

Starting from a univariate logistic regression study, a multivariate regression study is subsequently carried out to locate the variables that carry the greatest weight and determine the decisions to include a worker in one vulnerability group or another. The dependent variable has been recoded distinguishing two levels (low and medium-high risk level). From the variables that were significant in the univariate study, determining the odds ratio with the $95 \%$ confidence intervals, the variables that were essential to act as predictors of reaching a medium/high degree of vulnerability were selected for the multivariate. In this way, it is possible to detect which variables collect enough information to predict high vulnerability and high transmission medium/high level of vulnerability risk

\section{Results}

The variables contained in the protocol are shown in Figure 1. The scores ranges obtained in each block with the sample evaluated were personal aspects $(0-2)$, morbidity and its control $(0-8)$, labour sectors/work conditions $(0-3)$ and aspects of preventive management in the company $(0-3)$. The average overall score, considering all the blocks, is 3.69 points.

Valuing the relative weight of each group of variables in the overall assessment, the following results are obtained: 0.43 average score in personal aspects, which proportionally represents 1.23 of the total; morbidity 1.81 points, which represents 16.15 of the total; labour aspects, with an average score of 0.62 which proportionally represents 2.26 of the total; and preventive management, with an average score of 0.83 which proportionally represents 3.12 of the total in the degree of vulnerability.

The mean score values distribution corresponding to each variables block and in the vulnerability ranges considered in the assessment is shown in Table 1 and Figure 2. All the variables score and therefore influence the final score that defines the groups of vulnerability.

We observed that, from the obtained score, 15 of the 20 variables are strong (significant) to be in the medium/high vulnerability group: diabetes (with two levels: No/Yes), ATH (with two levels: No/Yes), obesity (with two levels: BMI < $30 / \mathrm{IMC} \geq 30$ ), tobacco use (with two levels: No/Yes), heart disease (with two levels: No/Yes), coagulation disorder (with two levels: No/Yes), chronic lung disease (with two levels: No/Yes), immunosuppression (with two levels: No/Yes), 


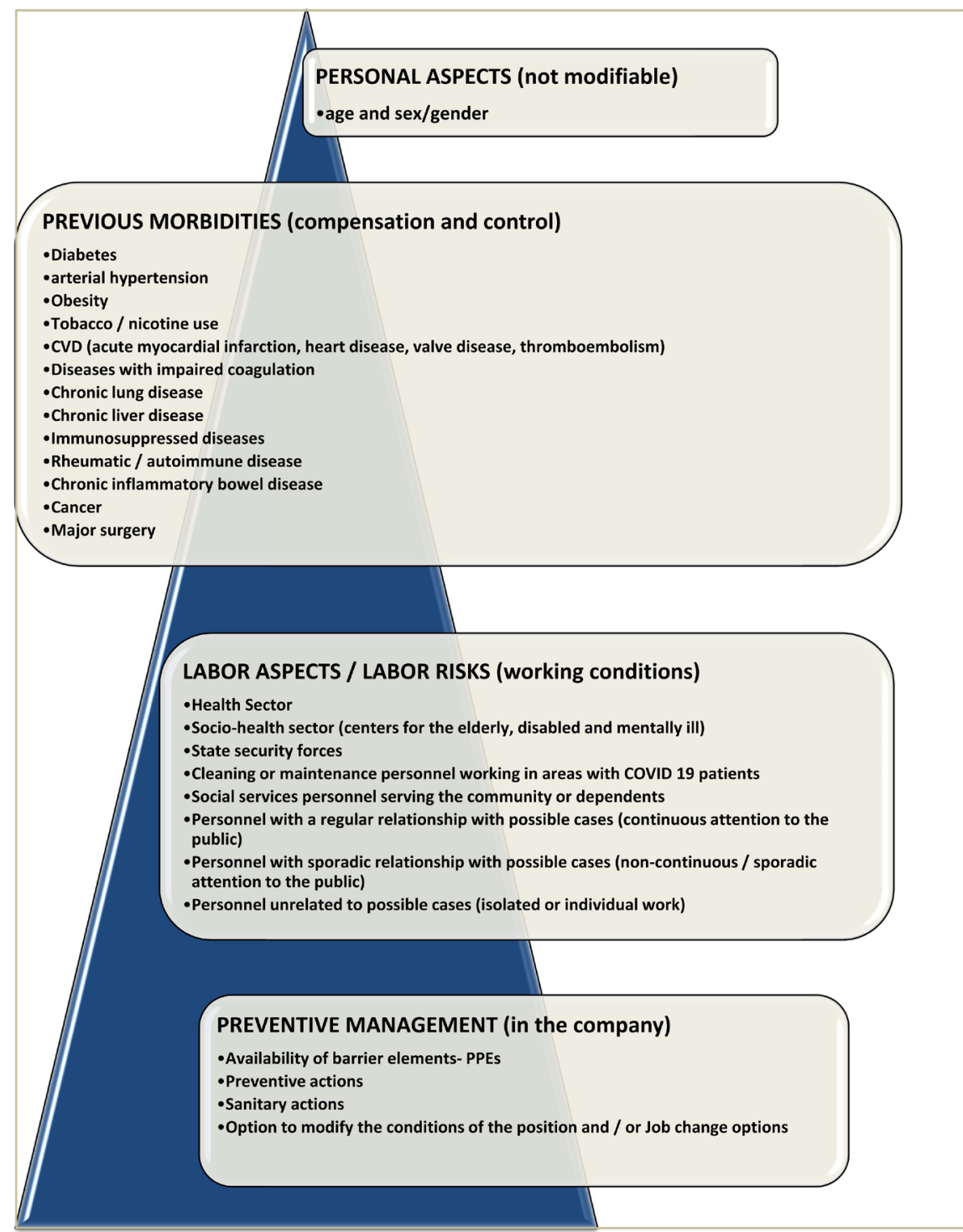

Figure 1. Variables included in the vulnerability assessment protocol against COVID-19.

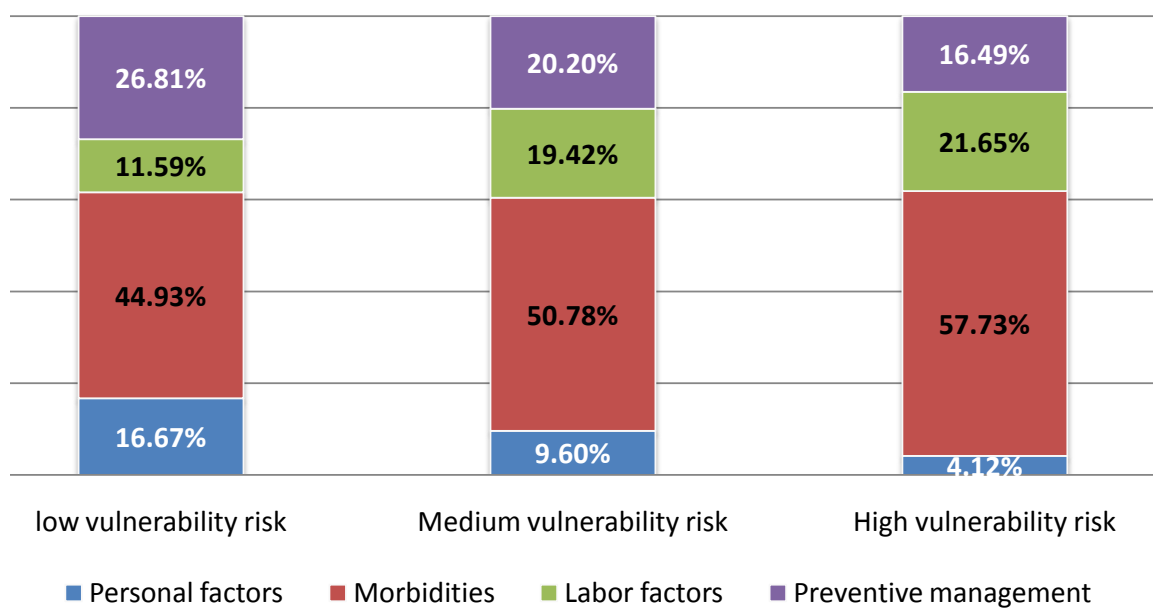

Figure 2. Distribution of the mean of each group of variables on the total value. 
Table 1. Average scores by groups of variables and weight with respect to the total.

\begin{tabular}{ccccc}
\hline \multicolumn{5}{c}{ Scores averages obtained by group of variables and vulnerability group } \\
\hline & Low score & Medium score & High score Medium Characteristics \\
\hline Personal Aspects & 0.4 & 0.48 & 0.36 & 0.43 \\
Previous Pathologies & 1.08 & 2.56 & 5.09 & 1.81 \\
Labor Aspects & 0.28 & 0.98 & 1.91 & 0.62 \\
Preventive Management & 0.64 & 1.02 & 1.45 & 0.82 \\
Average Vulnerability Score Group & 2.4 & 5.03 & 8.82 & 3.69 \\
\hline Weight of the mean of each group of characteristics over the total mean. \\
\hline Low score & Medium score & High score Medium Characteristics \\
\hline Personal Aspects & $16.67 \%$ & $9.60 \%$ & $4.12 \%$ & $11.78 \%$ \\
Previous Pathologies & $44.93 \%$ & $50.78 \%$ & $57.73 \%$ & $49.13 \%$ \\
Labor Aspects & $11.59 \%$ & $19.42 \%$ & $21.65 \%$ & $16.76 \%$ \\
Preventive Management & $26.81 \%$ & $20.20 \%$ & $16.49 \%$ & $22.33 \%$ \\
\hline
\end{tabular}

rheumatic disease (with two levels: No/Yes), cancer-recent, active or with sequelae (with two levels: No/Yes), major surgery-recent or with sequelae (with two levels: No/Yes), labor aspects (with two levels: 0 points/>0 points) and, in preventive management, the use of PPE (with two levels: Yes/No) and the modification options in the job (with two levels: Possible/No possible). The results are shown in Table 2.

When adjusting the multivariate model, 15 variables are selected and none of them lose strength in the presence of the others nor can they be omitted. This leaves a multivariate model with all 15 variables. The ones with the highest coefficient and, therefore, the highest weight in the probability of reaching a group of high or medium vulnerability are obesity, cardiovascular disease, cancer and coagulation alteration, immunosuppressed diseases, labor aspect/labor risk. The weight of the labour aspects due to inadequate working conditions stands out (Table 3 and Figure 3).

\section{Discussion}

Pandemics that have emerged in recent years, and especially the current one by COVID-19, highlight the need for communities to be prepared to manage them. The current situation shows that the best results are obtained by anticipating the damage or minimizing it with effective strategies to contain the infection and reduce the number of cases. Restrictive measures such as social distancing, confinement, early detection of cases, isolation, contact tracing and quarantine of those exposed have proven to be the most efficient actions to control the spread of the disease. However, experience suggests that future coordinated policies in the community will be needed to manage and mitigate the emergency [31].

The COVID-19 pandemic represents a global health, social and economic 
Table 2. Univariate logistic regression of the included variables and degree of significance. COVID-19 vulnerability protocol.

\begin{tabular}{|c|c|c|c|c|c|c|c|}
\hline Variable-reference & Coef & Err.Est & Wald & p-value & Odds Ratio & O.R inf. $95 \%$ & O.R sup. $95 \%$ \\
\hline \multicolumn{8}{|l|}{ Personal aspects } \\
\hline Age ( $\geq 60$ years). & 0.19 & 0.20 & 0.82 & 0.37 & 1.20 & 0.81 & 1.80 \\
\hline Gender (pregnant woman) & 0.52 & 0.40 & 1.72 & 0.19 & 1.68 & 0.77 & 3.65 \\
\hline \multicolumn{8}{|l|}{ Morbidities } \\
\hline Diabetes (yes) & 0.67 & 0.26 & 6.65 & 0.01 & 1.95 & 1.17 & 3.23 \\
\hline Arterial hypertension (yes) & 0.61 & 0.20 & 9.22 & 0.002 & 1.85 & 1.24 & 2.74 \\
\hline Obesity (BMI $\geq 30$ ) & 1.71 & 0.28 & 37.19 & $<0.001$ & 5.50 & 3.18 & 9.52 \\
\hline Tobacco (yes) & 1.33 & 0.29 & 20.73 & $<0.001$ & 3.78 & 2.13 & 6.70 \\
\hline Cardiovascular disease (yes ) & 1.48 & 0.30 & 23.99 & $<0.001$ & 4.39 & 2.43 & 7.92 \\
\hline Coagulation diseases (yes) & 1.73 & 0.51 & 11.56 & 0.001 & 5.63 & 2.08 & 15.22 \\
\hline Chronic lung diseases (yes) & 0.40 & 0.20 & 4.09 & 0.043 & 1.50 & 1.01 & 2.21 \\
\hline Chronic liver diseases (yes) & 1.31 & 1.16 & 1.27 & 0.260 & 3.70 & 0.38 & 35.80 \\
\hline Inmunosuppresed diseases (yes) & 1.38 & 0.38 & 13.17 & $<0.001$ & 3.99 & 1.89 & 8.42 \\
\hline Rheumatic disease (yes) & 0.94 & 0.47 & 3.90 & 0.048 & 2.55 & 1.01 & 6.45 \\
\hline Chronic inflammatory bowel disease (yes) & -0.14 & 0.60 & 0.06 & 0.808 & 0.87 & 0.27 & 2.77 \\
\hline Cancer (yes) & 1.58 & 0.57 & 7.67 & 0.01 & 4.87 & 1.59 & 14.94 \\
\hline Major surgery (yes) & 2.18 & 1.07 & 4.11 & 0.04 & 8.81 & 1.07 & 72.24 \\
\hline \multicolumn{8}{|l|}{ Labor aspect/Labor risk } \\
\hline Working conditions (punctuation $>0$ ) & 2.03 & 0.22 & 83.18 & $<0.001$ & 7.62 & 4.93 & 11.79 \\
\hline \multicolumn{8}{|l|}{ Preventive management in the company } \\
\hline Barrier elements-PPEs (no) & 1.22 & 0.30 & 16.97 & $<0.001$ & 3.370 & 1.890 & 6.007 \\
\hline Preventive actions Irregular/not protocolized & -0.67 & 0.23 & 8.625 & 0.003 & 0.510 & 0.325 & 0.799 \\
\hline Sanitary actions Irregular/not protocolized & 21.42 & 2321 & 0.00 & 0.999 & ---- & --- & --- \\
\hline Job modifications/job change (not possible) & 1.58 & 0.22 & 53.80 & $<0.001$ & 4.858 & 3.184 & 7.410 \\
\hline
\end{tabular}

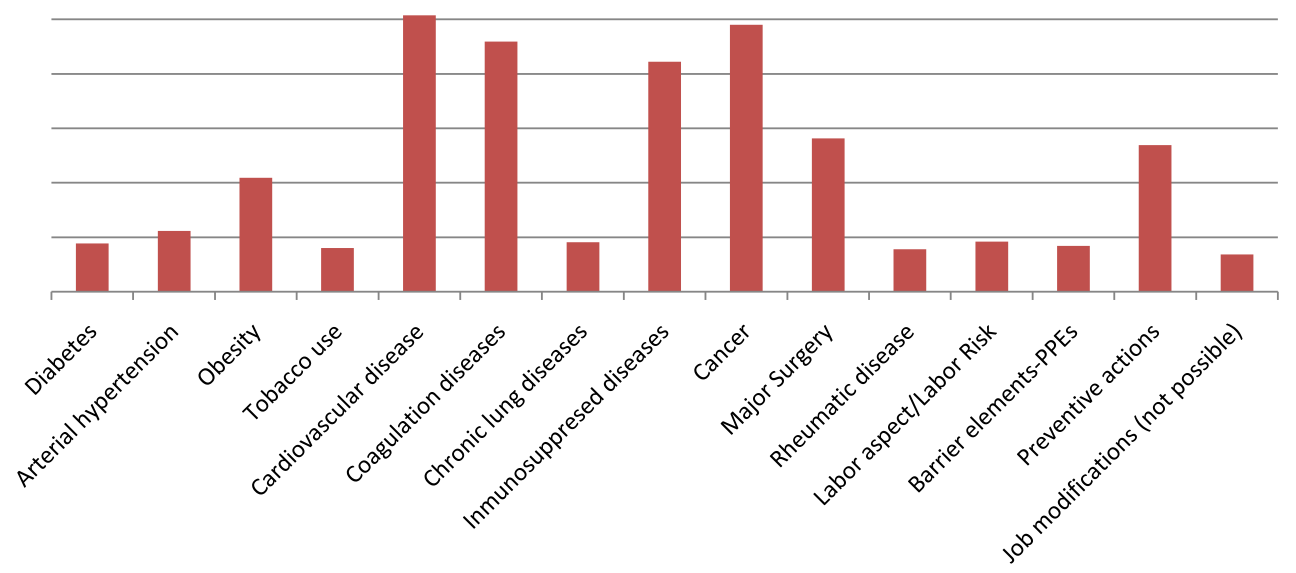

Figure 3. Vulnerability risk medium/high. 
Table 3. Multivariate study. Significance of variables-COVID-19 vulnerability protocol.

\begin{tabular}{lccccccc}
\hline \multicolumn{1}{c}{ Specified variables } & B & $\begin{array}{c}\text { Standard } \\
\text { error }\end{array}$ & Wald & p-value & Exp $(\beta)$ & I.C. $95 \%$ para $\operatorname{Exp}(\beta)$ \\
\hline Diabetes & 2.18 & 0.50 & 19.29 & $<0.001$ & 8.88 & 3.35 & 23.53 \\
Arterial hypertension & 2.41 & 0.44 & 30.41 & $<0.001$ & 11.16 & 4.74 & 26.31 \\
Obesity & 3.04 & 0.56 & 29.06 & $<0.001$ & 20.93 & 6.93 & 63.23 \\
Tobacco use & 2.08 & 0.54 & 14.96 & $<0.001$ & 8.00 & 2.79 & 22.96 \\
Cardiovascular disease & 3.93 & 0.66 & 35.53 & $<0.001$ & 50.76 & 13.95 & 184.61 \\
Coagulation diseases & 3.83 & 1.03 & 13.88 & $<0.001$ & 45.90 & 6.13 & 343.69 \\
Chronic lung diseases & 2.21 & 0.51 & 18.58 & $<0.001$ & 9.08 & 3.33 & 24.76 \\
Inmunosuppresed diseases & 3.74 & 0.71 & 28.14 & $<0.001$ & 42.20 & 10.59 & 168.19 \\
Cancer & 3.89 & 1.11 & 12.33 & $<0.001$ & 49.02 & 5.58 & 430.44 \\
Major Surgery & 3.29 & 1.66 & 3.95 & 0.047 & 26.94 & 1.05 & 693.19 \\
Rheumatic disease & 1.92 & 0.96 & 4.02 & 0.045 & 6.85 & 1.04 & 44.95 \\
Labor aspect/Labor Risk & 3.34 & 0.45 & 55.60 & $<0.001$ & 28.17 & 11.72 & 67.75 \\
Barrier elements-PPEs & 2.05 & 0.57 & 12.77 & $<0.001$ & 7.79 & 2.53 & 24.00 \\
Preventive actions & 2.22 & 0.51 & 19.22 & $<0.001$ & 9.21 & 3.41 & 24.87 \\
Job modifications/job change & 2.13 & 0.46 & 21.10 & $<0.001$ & 8.40 & 3.39 & 20.84 \\
(not possible) & & & & & & & \\
Constant (model fit) & -7.70 & 0.85 & 81.71 & $<0.001$ & 0.000 & & \\
\hline & & & & & & &
\end{tabular}

challenge. Effective blockade measures from the health point of view have led to the cessation of industrial and commercial production in most sectors, with reductions in jobs and layoffs [32]. The United States has reported a $14.7 \%$ increase in unemployment in April 2020 compared to 3.5\% in February [33]. Fear of job loss, along with social alienation, confinement, economic instability and uncertainty, will result in a strong psychosocial impact that governments will need to address [34]. One of the proposed preventive strategies is to identify groups with greater psychological vulnerability based on sociodemographic and occupational contextual factors [35].

Probably one of the aspects with the greatest impact on this socio-economic and health vision is the labour world, where prevention and protection of workers and business management must be combined, and where the concept of vulnerability applied to exposed workers fits in.

Researchers are asking themselves this question: Is success compatible with vulnerability? The current crisis has highlighted a common perception: that vulnerability can be lethal in a competitive research market. However, taking care of mental health is important for everyone, and conducting research with reproducible experiments that stand the test of time requires prioritizing physical and mental health and emotional well-being [36].

In Vietnam, the health problems, behaviour and access to health services of 
industrial workers are examined to determine effective and appropriate control measures for COVID-19, minimising the risk. The findings suggest a high risk of disease spread among industrial workers and more severe conditions when they are infected [37].

The environmental relationship and occupational aspects with long-term exposure to xenobiotic mixtures and the inherent immunodeficiency of chronic diseases and epidemics/pandemics is a reality and should be taken into account if the biochemical and biophysical properties of SARS-CoV-2 are considered to have immunopathological implications [38].

The COVID-19 Vulnerability Assessment Protocol proposes to estimate quantifying the risk and probability of complications in workers from SARS-CoV2 infection, to address the various health effects during the current pandemic crisis and the actions needed to prevent similar effects in outbreaks or future epidemics/pandemics. This would provide a quantified assessment that could be used as an Occupational Vulnerability Index (OVI), similar to the existing Social Vulnerability Index (VSI).

Without a doubt, one of the groups where the concept of occupational vulnerability has the most relevant meaning is health. Healthcare workers, who are in close contact with affected patients, face specific risks and a greater probability of contagion, so early prevention and early detection strategies are required to mitigate the risks. A detailed assessment of the factors influencing transmission is also needed in order to make preventive recommendations aimed at empowering health workers through education and training and protecting them, so that it is possible to combine their health role with action on the factors influencing compliance with infection control measures [39].

The concept of social vulnerability COVID-19 already exists, which is treated in the scientific literature and is associated with increased mortality from COVID-19. High social vulnerability is quantified by means of the social vulnerability index (VSI) and allows for predictive and preventive actions in populations that should be the object of public policy actions to help alleviate the pandemic burden on these more vulnerable populations.

The concept of occupational vulnerability is evaluated from a social point of view [40] [41] or related to aspects such as work injuries [42] [43], but in all cases without quantifying and in no case related to the current COVID-19 pandemic.

The objective of this protocol is to assess the labour vulnerability of the COVID-19 by integrating individual variables of the worker, his working conditions and the preventive actions of his company against COVID-19, and we propose the resulting Labour Vulnerability Index (LVI) to quantify it.

The main strength is to be the first proposal as such and to have as a starting point the results of an initial assessment with an indicative sample, as well as the ease of its completion, quantification and risk stratification. The main bias is the scarce or non-existent representativeness of some labour groups and not being able to have a larger sample. 
We consider the development of new studies as open work line, as well as making an incidence assessment and lethality adjusted to the vulnerability degree that will allow us to validate this work tool in the near future.

\section{Conclusions}

The results obtained with the application of the COVID-19 vulnerability assessment protocol allow us to highlight cancer, coagulation alterations and cardiovascular disease and as an occupational risk, work in the health sector and inadequate preventive conditions.

The final result estimates the medium-high risk of vulnerability and can be useful as an Occupational Vulnerability Index (OVI) and facilitate preventive decision-making in companies.

\section{Conflicts of Interest}

The authors declare no conflicts of interest regarding the publication of this paper.

\section{References}

[1] Real Academia Española (2020) Diccionario de la lengua española. 23a Edition. https://dle.rae.es

[2] Hilhorst, D. and Bankoff, G. (2004) Introduction: Mapping Vulnerability. In: Bankoff, G., Frerks, G. and Hilhorst, D., Eds., Mapping Vulnerability. Disasters, Development and People, Earthscan, Londres, 37.

[3] Bueno Sánchez, E. (2006) Una exploración de la vulnerabilidad sociolaboral en el estado de Zacates. Revista Electrónica Zacatecana sobre Población y Sociedad. Año 6, Tercera Era, No. 29.

[4] WHO Europe. Answers to Follow-Up Questions from CAFE. https://www.greenfacts.org/es/glosario/tuv/vulnerabilidad-en-ciencias-de-la-salud.h tm\#: :text=de\%20la\%20salud

[5] Naya, A., Islam, S.J., Mehta, A., Ko, Y.-A., Patel, S.A., Goyal, A., et al. (2020) Impact of Social Vulnerability on COVID-19 Incidence and Outcomes in the United States. https://www.medrxiv.org/content https://doi.org/10.1101/2020.04.10.20060962

[6] Correa-Agudelo, E., Mersha, T., Hernandez, A., Branscum, A.J., MacKinnon, N.J. and Cuadros, D.F. (2020) Identification of Vulnerable Populations and Areas at Higher Risk of COVID-19 Related Mortality in the U.S. https://doi.org/10.1101/2020.07.11.20151563

[7] Karaye, I.M. and Horney, J.A. (2020) The Impact of Social Vulnerability on COVID-19 in the U.S.: An Analysis of Spatially Varying Relationships. American Journal of Preventive Medicine.

[8] Wyper, G.M.A., Assunção, R., Cuschieri, S., Devleeschauwer, B., Fletcher, E., Haagsma, J.A., et al. (2020) Population Vulnerability to COVID-19 in Europe: A Burden of Disease Analysis. Archives of Public Health, 78, 47. https://doi.org/10.1186/s13690-020-00433-y

[9] Boccardi, V., Ruggiero, C. and Mecocci, P. (2020) COVID-19: A Geriatric Emergency. Geriatrics (Basel), 5, 24. https://doi.org/10.3390/geriatrics5020024 
[10] Masmejan, S., Pomar, L., Lepigeon, K., Favre, G., Baud, D. and Rieder, W. (2020) COVID-19 and Pregnancy. Revue Médicale Suisse, 16, 944-946.

[11] Ministerio de Sanidad (2020) Manejo de la mujer embarazada y el recién nacido con COVID-19. Documento Técnico de 13 de mayo de.

[12] The Epidemiological Characteristics of an Outbreak of 2019 Novel Coronavirus Diseases (COVID-19)_China, 2020. http://weekly.chinacdc.cn/en/article/id/e53946e2-c6c4-41e9-9a9b-fea8db1a8f51

[13] Fang, L., Karakiulakis, G. and Roth, M. (2020) Are Patients with Hypertension and Diabetes Mellitus at Increased Risk for COVID-19 Infection? The Lancet Respiratory Medicine, 8, e21. https://doi.org/10.1016/S2213-2600(20)30116-8

[14] Zhang, W., Xu, Y.-Z., Liu, B., Wu, R., Yang, Y.-Y., Xiao, X.-Q., et al. (2014) Pioglitazone Upregulates Angiotensin Converting Enzyme 2 Expression in Insulin-Sensitive Tissues in Rats with High-Fat Diet-Induced Nonalcoholic Steatohepatitis. Scientific World Journal, 2014, Article ID: 603409. https://doi.org/10.1155/2014/603409

[15] Hussain, A., Vasas, P. and El-Hasani, S. (2020) Obesity as a Risk Factor for Greater Severity of COVID-19 in Patients with Metabolic Associated Fatty Liver Disease. Metabolism, 108, Article ID: 154256. https://doi.org/10.1016/j.metabol.2020.154256

[16] Muscogiuri, G., Pugliese, G., Barrea, L., Savastano, S. and Colao, A. (2020) Obesity: The "Achilles Heel" for COVID-19? Metabolism-Clinical and Experimental, 108, Article ID: 154251.

https://www.metabolismjournal.com/article/S0026-0495(20)30115-3/abstract

[17] Long, B., Brady, W.J., Koyfman, A. and Gottlieb, M. (2020) Cardiovascular Complications in COVID-19. American Journal of Emergency Medicine. https://doi.org/10.1016/j.ajem.2020.04.048

[18] Driggin, E., Madhavan, M.V., Bikdeli, B., Chuich, T., Laracy, J., Biondi-Zoccai, G., et al. (2020) Cardiovascular Considerations for Patients, Health Care Workers, and Health Systems during the COVID-19 Pandemic. Journal of the American College of Cardiology, 75, 2352-2371. https://doi.org/10.1016/j.jacc.2020.03.031

[19] Tal-Singer, R. and Crapo, J.D. (2020) COPD at the Time of COVID-19: A COPD Foundation Perspective. Chronic Obstructive Pulmonary Diseases (Miami, Fla.), 7, 73-75. https://doi.org/10.15326/jcopdf.7.2.2020.0149

[20] Li, Y. and Xiao, S.-Y. (2020) Hepatic Involvement in COVID-19 Patients: Pathology, Pathogenesis, and Clinical Implications. Journal of Medical Virology.

[21] Feng, G., Zheng, K.I., Yan, Q.-Q., Rios, R.S., Targher, G., Byrne, C.D., et al. (2020) COVID-19 and Liver Dysfunction: Current Insights and Emergent Therapeutic Strategies. Journal of Clinical and Translational Hepatology, 8, 18-24. https://doi.org/10.14218/JCTH.2020.00018

[22] SICAM (2020) Recomendaciones de la sociedad de inmunología de la comunidad de Madrid para la prevención y manejo de la infección por el coronavirus (COVID-19) en pacientes con inmunodeficiencia. https://www.inmunologia.org/Upload/Documents/1/5/0/1506.pdf

[23] Ministerio de Sanidad (2020) Guía de prevención y control frente al COVID19 en residencias de mayores y otros centros de servicios sociales de carácter residencial. https://www.mscbs.gob.es/profesionales/saludPublica/ccayes/alertasActual/nCov-C hina/documentos/Residencias_y_centros_sociosanitarios_COVID-19.pdf

[24] Canova, V., Lederer Schläpfer, H., Piso, R.J., Droll, A., Fenner, L., Hoffmann, T., et al. (2020) Transmission Risk of SARS-CoV-2 to Healthcare Workers-Observational Results of a Primary Care Hospital Contact Tracing. Swiss Medical Weekly, 150, 
w20257. https://doi.org/10.4414/smw.2020.20257

[25] Vicente-Herrero, T., de la Torre, V., del Campo Balsa, T., Barbero, L.R., Montero, A.F. and Garrido, J.C. (2020) Proposed Protocol for Risk Assessment and Stratification. Occupational Diseases and Environmental Medicine, 8, 99-110. https://doi.org/10.4236/odem.2020.83008

[26] España. Ministerio de Sanidad. Procedimiento de actuación para los servicios de prevención de riesgos laborales frente a la exposición al SARS-CoV-2. https://www.mscbs.gob.es/en/profesionales/saludPublica/ccayes/alertasActual/nCov -China/documentos/PrevencionRRLL_COVID-19.pdf

[27] España. Real Decreto-ley 6/2020, de 10 de marzo, por el que se adoptan determinadas medidas urgentes en el ámbito económico y para la protección de la salud pública. Boletín Oficial del Estado núm. 62, de 11 de marzo de 2020.

[28] España. Real Decreto 39/1997, de 17 de enero, por el que se aprueba el Reglamento de los Servicios de Prevención. Boletín Oficial del Estado núm. 27, de 31 de enero de 1997.

[29] España. Ley Orgánica 3/2018, de 5 de diciembre, de Protección de Datos Personales y garantía de los derechos digitales. Boletín Oficial del Estado núm. 294, de 06 de diciembre de 2018.

[30] Spanish Association of Specialist in Occupational Medicine. COVID-19 valoración de vulnerabilidad propuesta de protocolo. Resultados del testeo en muestra población laboral.

http://www.aeemt.com/web/wp-content/uploads/2020/08/PROTOCOLO-VULNER ABILIDAD-COVID-19-AEEMT-PRIMEROS-RESULTADOS-EN-MUESTRA-DETRABAJADORES.pdf

[31] Khanna, R.C., Cicinelli, M.V., Gilbert, S.S., Honavar, S.G. and Murthy, G. (2020) COVID-19 Pandemic: Lessons Learned and Future Directions. Indian Journal of Ophthalmology, 68, 703-710. https://doi.org/10.4103/ijo.IJO_843_20

[32] Gómez, A.M.A. and Favorito, L.A.. (2020) The Social, Economic and Sanitary Impact of COVID-19 Pandemic. International Brazilian Journal of Urology, 46, 3-5. http://www.scielo.br/scielo.php?script=sci_arttext\&pid=S1677-55382020000700003 \&lng=en https://doi.org/10.1590/s1677-5538.ibju.2020.s1ed2

[33] The Economist. https://www.economist.com

[34] Brooks, S.K., Webster, R.K., Smith, L.E., Woodland, L., Wessely, S., Greenberg, N., et al. (2020) The Psychological Impact of Quarantine and How to Reduce It: Rapid Review of the Evidence. The Lancet, 395, 912-920. https://doi.org/10.1016/S0140-6736(20)30460-8

[35] Becerra-García, J.A., Giménez Ballesta, G., Sánchez-Gutiérrez, T., Barbeito Resa, S. and Calvo Calvo, A. (2020) Psychopathological Symptoms during COVID-19 Quarantine in Spanish General Population: A Preliminary Analysis Based on Sociodemographic and Occupational-Contextual Factors. Revista Española de Salud Pública, 94, e202006059.

[36] Hunt, J.E. (2020) COVID-19 and the Research Community: Being Vulnerable. Elife, 9, e59285. https://doi.org/10.7554/eLife.59285

[37] Bach, X.T., Giang, T.V., Latkin, C.A., Pham, H.Q., Phan, H.T., Le, H.T., et al. (2020) Characterize Health and Economic Vulnerabilities of Workers to Control the Emergence of COVID-19 in an Industrial Zone in Vietnam. Safety Science, 129, Article ID: 104811. https://doi.org/10.1016/j.ssci.2020.104811

[38] Tsatsakis, A., Petrakis, D., Nikolouzakis, T.K., Docea, A.O., Calina, D., Vinceti, M., 
et al. (2020) COVID-19, an Opportunity to Reevaluate the Correlation between Long-Term Effects of Anthropogenic Pollutants on Viral Epidemic/Pandemic Events and Prevalence. Food and Chemical Toxicology, 141, Article ID: 111418. https://doi.org/10.1016/j.fct.2020.111418

[39] Yiwen, K., Hegney, D. and Drury, V. (2010) A Comprehensive Systematic Review of Healthcare Workers' Perceptions of Risk from Exposure to Emerging Acute Respiratory Infectious Diseases and the Perceived Effectiveness of Strategies Used to Facilitate Healthy Coping in Acute Hospital and Community Healthcare Settings. JBI Library of Systematic Reviews, 8, 917-971. https://doi.org/10.11124/jbisrir-2010-150

[40] Lay, A.M., Kosny, A., Aery, A., Flecker, K., Smith, P.M. (2018) The Occupational Health and Safety Vulnerability of Recent Immigrants Accessing Settlement Services. Canadian Journal of Public Health, 109, 303-311. https://doi.org/10.17269/s41997-018-0063-4

[41] Rupakheti, D., Pradhan, P.M.S. and Basel, P. (2018) Occupational Safety and Health Vulnerability among Brick Factory Workers in Dhading District, Nepal. Annals of Global Health, 84, 481-487. https://doi.org/10.29024/aogh.2313

[42] Yanar, B., Lay, M. and Smith, P.M. (2019) The Interplay between Supervisor Safety Support and Occupational Health and Safety Vulnerability on Work Injury. Safety and Health at Work, 10, 172-179. https://doi.org/10.1016/j.shaw.2018.11.001

[43] Nadalin, V. and Smith, P.M. (2020) Examining the Impact of Occupational Health and Safety Vulnerability on Injury Claim Reporting in Three Canadian Provinces. American Journal of Industrial Medicine, 63, 435-441.

https://doi.org/10.1002/ajim.23094 